\title{
Glucagon-like Peptide 1 Conjugated to Recombinant Human Serum Albumin Variants with Modified Neonatal Fc Receptor Binding Properties. Impact on Molecular Structure and Half-Life
}

Bukrinski, Jens T.; Sønderby, Pernille; Antunes, Filipa; Andersen, Birgitte; Schmidt, Esben G. W.; Peters, Güenther H. J.; Harris, Pernille

\author{
Published in: \\ Biochemistry
}

Link to article, DOI:

10.1021/acs.biochem.7b00492

Publication date:

2017

Document Version

Peer reviewed version

Link back to DTU Orbit

Citation (APA):

Bukrinski, J. T., Sønderby, P., Antunes, F., Andersen, B., Schmidt, E. G. W., Peters, G. H. J., \& Harris, P. (2017). Glucagon-like Peptide 1 Conjugated to Recombinant Human Serum Albumin Variants with Modified Neonatal Fc Receptor Binding Properties. Impact on Molecular Structure and Half-Life. Biochemistry, 56(36), 4860-4870. https://doi.org/10.1021/acs.biochem.7b00492

\section{General rights}

Copyright and moral rights for the publications made accessible in the public portal are retained by the authors and/or other copyright owners and it is a condition of accessing publications that users recognise and abide by the legal requirements associated with these rights.

- Users may download and print one copy of any publication from the public portal for the purpose of private study or research.

- You may not further distribute the material or use it for any profit-making activity or commercial gain

- You may freely distribute the URL identifying the publication in the public portal 


\section{GLP-1 conjugated to rHSA variants with modified FcRn binding properties. Impact on molecular structure and half-life \\ Jens Thostrup Bukrinski, Pernille Sønderby, Filipa Antunes, Birgitte Andersen, Esben Gjerloeff Wedebye Schmidt, Guenther H. H. J. Peters, and Pernille Harris}

Biochemistry, Just Accepted Manuscript • DOI: 10.1021/acs.biochem.7b00492 • Publication Date (Web): 11 Aug 2017

Downloaded from http://pubs.acs.org on August 21, 2017

\section{Just Accepted}

"Just Accepted" manuscripts have been peer-reviewed and accepted for publication. They are posted online prior to technical editing, formatting for publication and author proofing. The American Chemical Society provides "Just Accepted" as a free service to the research community to expedite the dissemination of scientific material as soon as possible after acceptance. "Just Accepted" manuscripts appear in full in PDF format accompanied by an HTML abstract. "Just Accepted" manuscripts have been fully peer reviewed, but should not be considered the official version of record. They are accessible to all readers and citable by the Digital Object Identifier (DOI $\left.{ }^{\circ}\right)$. "Just Accepted" is an optional service offered to authors. Therefore, the "Just Accepted" Web site may not include all articles that will be published in the journal. After a manuscript is technically edited and formatted, it will be removed from the "Just Accepted" Web site and published as an ASAP article. Note that technical editing may introduce minor changes to the manuscript text and/or graphics which could affect content, and all legal disclaimers and ethical guidelines that apply to the journal pertain. ACS cannot be held responsible for errors or consequences arising from the use of information contained in these "Just Accepted" manuscripts. 


\title{
GLP-1 conjugated to rHSA variants with modified FcRn binding properties. Impact on molecular structure and half-life
}

\author{
Jens T. Bukrinski ${ }^{2}$, Pernille Sønderby ${ }^{1}$, Filipa Antunes ${ }^{3}$, Birgitte Andersen ${ }^{2}$, Esben G. W. Schmidt ${ }^{2}$, \\ Günther H.J. Peters ${ }^{1}$, Pernille Harris ${ }^{1 *}$ \\ ${ }^{1}$ Department of Chemistry, Technical University of Denmark, Kemitorvet 207, \\ DK-2800 Kgs. Lyngby, Denmark \\ ${ }^{2}$ Novozymes A/S, Krogshøjvej 36, Bagsværd, DK-2880, Denmark \\ ${ }^{3}$ Albumedix Ltd, Castle Court, 59 Castle Boulevard, Nottingham, NG7 1FD, United Kingdom \\ E-mail: *ph@kemi.dtu.dk
}

\begin{abstract}
Glucagon-like peptide 1 (GLP-1) is a small incretin hormone stimulated by food intake, resulting in an amplification of the insulin response. Though interesting as a drug candidate for the treatment of type 2 diabetes mellitus, its short plasma half-life of less than 3 minutes limits its clinical use. A strategy to extend the half-life of GLP-1 utilizes the long half-life of human serum albumin (HSA) by combining the two via chemical conjugation or genetic fusion. HSA has a plasma half-life of around 21 days owing to its interaction with the neonatal $F c$ receptor $(\mathrm{FcRn})$ expressed in endothelial cells of blood vessels, which rescues circulating HSA from lysosomal degradation. We have conjugated GLP-1 to C34 of native sequence recombinant HSA (rHSA) and two rHSA variants; one with increased and one with decreased binding affinity to $h \mathrm{FcRn}$. We have investigated the impact of conjugation on FcRn binding affinities, GLP-1 potency and pharmacokinetics, combined with the solution structure of the rHSA variants and GLP-1 albumin conjugates. The solution structures, determined by small angle X-ray scattering, show the GLP-1 pointing away from the surface of rHSA. Combining the solution structures with the available structural information on the FcRn and GLP-1 receptor (GLP-1R) obtained from X-ray crystallography, we can explain the observed in-vitro and in-vivo behaviour. We conclude that the conjugation of GLP-1 to rHSA does not affect the interaction between rHSA and FcRn, while the observed decrease in the potency of GLP-1 can be explained by a steric hindrance of GLP-1 binding to its receptor.

Abbreviations: HSA: human serum albumin; rHSA: recombinant human serum albumin; GLP-1: glucagon-like peptide 1; WT: wild-type; DPP-VI: dipeptidyl-peptidase-IV; IgG: Immunoglobulin G; NMR: nuclear magnetic resonance; FcRn: neonatal Fc receptor; SAXS: small angle X-ray scattering. GLP-1-PEG-mal: HGEGTFTSDVSSYLEGQAAKEFIAWLVKGR-K-(8-amino3,6,dioxaoctanoyl-maleimidopropionyl)); NMRI: naval medical research institute; PK: pharmacokinetics
\end{abstract}

Keywords: GLP-1, glucagon-like peptide 1, albumin, HSA, SAXS, small angle X-ray scattering, pharmaco kinetics, pk, FcRn binding, albumin conjugation, half-life extension 


\section{INTRODUCTION}

According to the International Diabetes Federation ${ }^{1}$ the number of diabetes patients, which in 2015 was 415 million world wide will have increased to 642 million people in 2040. Since the approval of Byetta $^{\circledR}$ by the US Food and Drug administration in 2005 as the first in class glucagon-like peptide 1 (GLP-1) receptor agonist, GLP-1 has been successfully used for the treatment of diabetes providing effective control of blood glucose levels, lowering of systolic blood pressure and reduction of body weight ${ }^{2}$.

GLP-1 is a 30 amino acid (7-36-amide; UniProt: P01275) peptide incretine hormone and its secretion is stimulated by food intake ${ }^{3}$, resulting in an amplification of the insulin response ${ }^{4,5}$. The reported plasma half-life of GLP-1 is, however, less than 3 minutes ${ }^{6-9}$ wherefore the native peptide is unsuitable as a drug candidate. There are two main reasons for the short half-life; due to the small size (molar mass of $3.3 \mathrm{kDa}$ ) GLP-1 is cleared rapidly by renal filtration ${ }^{8}$. Furthermore, a specific inactivation mechanism exists as GLP-1 is sensitive to dipeptidyl-peptidase-IV (DPP-IV) hydrolysis and is therefore rapidly inactivated in human plasma by truncation of the N-terminal His-Ala forming the inactive 9-36-amide degradation product ${ }^{10}$. Studies using continuous administration by intravenous infusion of GLP-1, indicate a clinical relevance of GLP-1 as drug candidate when the action of the peptide is sufficiently extended ${ }^{11}$, and three different approaches have been pursued to extend the circulatory half-life of GLP-1: Reduction of the sensitivity towards DPP-IV degradation, decrease of the rate of passive renal clearance and third, mobilization of active recycling mediated by the FcRn. In Table S1, we show a selection of GLP-1 variants with their reported half-life. Reduction of sensitivity towards proteolytic inactivation by DPP-IV significantly extends the half-life of GLP1 from minutes to hours. Examples of this approach are the development of drugs such as exenatide 12 and lixisenetide ${ }^{13}$, where the half-life was successfully increased from a few minutes to 2.4 and 3-4 hours, respectively, allowing for twice and once daily administration. Although a lowering of the DPP-IV induced degradation results in a $\sim 50$ fold increase in the half-life, renal filtration is still very efficient in clearing the peptides. Increasing size to diminish renal clearance will additionally increase the half-life of GLP-1, and this approach has been utilized in the development of several drug candidates such as liraglutide, which is a human GLP-1 analogue lipidated at position 16 allowing for complex formation with endogenous HSA. The lipidation additionally induces a concentration independent multimerization of the peptide resulting in a 6-8 fold increased size to approximately 30 $\mathrm{kDa}^{14}$. The lipidation results in a plasma half-life of $11-13 \mathrm{hrs}{ }^{15}$. However, it is unclear which of the species, the HSA-liraglutide complex or the liraglutide multimer, that are pharmacologically relevant accounting for observed extension of the half-life. Another approach to increase the size is used in LY2428757. Here, GLP-1 is pegylated resulting in a half-life of 2.5 days in cynomalgus monkey ${ }^{16}$. A similar half-life of 2.5 days in cynomolgus monkey was achieved from XTENylation by fusion of an unstructured recombinant polypeptide of 864 amino acids to exenatide ${ }^{17}$.

Additional prolongation of half-life is achieved by covalent attachment of exenatide to the Fc domain of Immunoglobulin G (IgG) ${ }^{18}$ or to rHSA ${ }^{19}$. Both IgG and HSA have an extraordinary long halflife of 21 days. The long half-life is a result of an active rescue mechanism where HSA ${ }^{20-22}$ and IgG ${ }^{23-26}$ are captured by the FcRn and recycled. FcRn rescues the proteins in the endosomes after 
pinocytosis through a strong interaction triggered by the relatively low $\mathrm{pH}(\sim \mathrm{pH} 6-6.5)$ in this cellular compartment. Binding to FcRn prevents HSA and IgG from entering into the lysosomal pathway for destruction. Instead the proteins are released into the extracellular space triggered by an increase in $\mathrm{pH}(\sim \mathrm{pH} 7.4)$. An extensive review on albumin's inherent properties making it an efficient drug delivery platform is given in Sleep (2015) ${ }^{27}$. Mustering of the FcRn recycling mechanism by covalent attachment to the Fc domain of IgG or to rHSA, further extends the half-life by a factor of $\sim 2.5$. Dulaglutide, an exenatide-Fc fusion protein, has thus been reported to have a circulatory half-life of 4 days. Albiglutide, a (GLP-1 analogue) 2 -albumin fusion and CJC-1134, an exenatide-albumin conjugation have been reported to have a half-life of $6^{28,29}$ and $8^{30}$ days, respectively. Semaglutide ${ }^{31}$ is a once-weekly GLP-1 analogue with two amino acid substitutions, giving rise to decreased invivo degradation by DPP-IV, and lipidation at position number 26, allowing for complex formation between endogenous HSA and semaglutide, resulting in a plasma half-life of approximately 7 days 32. This compares to the half-life observed of the GLP-1 analogues that are covalently linked to rHSA and suggests to us that the complex formed is resilient and enabling FcRn recycling of the complex.

A potential concern is that conjugation of drugs to albumin can have an adverse effect on the binding of albumin to $\mathrm{FcRn}$ resulting in limited half-life extension, and also resulting in a decreased potency of the conjugate by affecting the binding of the drug to its target. The latter can be assessed by threedimensional (3-D) structures of drug-target complexes providing an atomistic insight. 3-D crystal structures of GLP-1 variants conjugated to HSA are not available. However, some structural insight is provided by the solution structures of GLP-1 (pdbid: 1D0R) ${ }^{33}$ and exendin-4 (pdbid: 1JRJ) that both show a helical peptide with flexible $\mathrm{N}$-and $\mathrm{C}$-terminals.

The 3-D structures of the extracellular part of the GLP-1R in complex with exendin-4 (pdb ids: 3C5T, 3C59) ${ }^{34}$, GLP-1 (pdbid: 3IOL) ${ }^{35}$ and semaglutide (pdbid: 4ZGM) ${ }^{32}$ show similar binding patterns with both hydrophobic and hydrophilic interactions being responsible for the binding and that the Cterminal part of the helix binds to the extracellular part of the receptor. A two-step binding mechanism of GLP-1 to the receptor has been proposed involving initial binding of the C-terminal of the peptide to the extracellular part of the GLP-1R. This facilitates the interaction of the N-terminal of GLP-1 to the core part of the GLP-1R (reviewed by Hoare $(2005){ }^{36}$ ). The receptor is a seven-transmembrane $\mathrm{G}$ protein-coupled receptor ${ }^{37}$ and the structure of the full-length receptor with a peptide agonist bound has been solved by X-ray crystallography ${ }^{38}$ (pdbid: $5 \mathrm{NX} 2$ ).

We set out to study the effect of conjugating GLP-1 to C34 of three variants of rHSA. Wild type rHSA (WT-albumin), a variant known to have high binding affinity to FcRn (HB-albumin; K573P) ${ }^{39}$ and a variant known to have very low binding affinity to FcRn (NB-albumin; K500A) ${ }^{40}$. The FcRn binding kinetics, the GLP-1R agonist activity in 3 TC6 pancreatic tumour cells and the pharmacokinetics in mice were determined. These results were complimented by structural models of the GLP-1 albumin conjugates derived from small angle X-ray scattering (SAXS) allowing modelling of the molecular interactions explaining the experimental observations.

\section{METHODS}

\section{Albumin variants}


WT-, NB-, and HB-albumin were produced by secretion from yeast as described elsewhere ${ }^{40}$, followed by a 2-step purification using AlbuPure ${ }^{\circledR}$ (ProMetic BioSciences Ltd UK) and diethylaminoethyl weak anion exchange Sepharose Fast Flow (GE Healthcare).

GLP-1 with a C-terminal maleimide group was purchased from PolyPeptide Laboratories France SAS (Sequence of maleimide coupled GLP-1: HGEGTFTSDVSSYLEGQAAKEFIAWLVKGR-K-(8amino-3,6, dioxaoctanoyl-maleimidopropionyl)) (GLP-1-PEG-mal). The maleimide group reacts with the free C34 of rHSA hereby conjugating GLP-1 to rHSA. The three GLP-1-PEG-albumin variants were GLP-1-PEG-WT-albumin, GLP-1-PEG-NB-albumin and GLP-1-PEG-HB-albumin.

The sequence and identity of all compounds were confirmed by MS (data not shown).

Buffer components and salts for the purifications were purchased from Sigma Aldrich. All solutions were prepared using water for injection (WFI) (HyClone WFI, Thermo scientific). The conjugation reaction was performed in PBS (Medicago, Sweden) at $\mathrm{pH} 7.1$ with 1.5 molar excess of rHSA to GLP-1-PEG-mal. The reaction was performed over night at room temperature with gentle shaking and terminated by addition of 0.5 volume WFI followed by $\mathrm{pH}$ adjustment to 5.3 with acetic acid. Unconjugated GLP-1-PEG-mal was removed by AlbuPure® matrix (ProMetic BioSciences) chromatography; unconjugated rHSA and GLP-1 albumin conjugates were eluted with $50 \mathrm{mM}$ ammonium-acetate, $10 \mathrm{mM}$ octanoate $\mathrm{pH} 7.0^{41}$. To the affinity purified material, ammonium sulphate was added to a final concentration of $0.5 \mathrm{M}$ for separation of unconjugated and conjugated rHSA on a HiTrap Butyl sepharose HP column (GE Healthcare) equilibrated in $0.5 \mathrm{M}\left(\mathrm{NH}_{4}\right)_{2} \mathrm{SO}_{4}, 20 \mathrm{mM} \mathrm{Na}-$ phosphate, $5 \mathrm{mM}$ Na-octanoate $\mathrm{pH}$ 7.0. GLP-1-PEG-albumin was eluted with a linear gradient from $0.5 \mathrm{M}\left(\mathrm{NH}_{4}\right)_{2} \mathrm{SO}_{4}, 20 \mathrm{mM}$ Na-phosphate, $5 \mathrm{mM} \mathrm{Na}$-octanoate $\mathrm{pH} 7.0$ to WFI. Mono-conjugates eluted at approx. $0.25 \mathrm{M}\left(\mathrm{NH}_{4}\right)_{2} \mathrm{SO}_{4}$. The purified mono-conjugate was added $1 / 10$ volume of $10 \times \mathrm{PBS}$ to control $\mathrm{pH}$. The conjugation was stabilized by hydrolysis (ring-opening) of the maleimide ring ${ }^{42}$ by addition of glycine to $25 \mathrm{mM}$ and $\mathrm{pH}$ adjustment to 9.0. The hydrolysis was performed for $20 \mathrm{hrs}$ at room temperature and terminated by neutralizing to $\mathrm{pH}$ 7.0. The HiTrap Butyl sepharose HP purification was repeated to obtain the stabilized mono-conjugate, and the samples were transferred into PBS pH 7.4 using VivaSpin ${ }^{\circledR} 20$ (Sartorius Stedim) with a $30 \mathrm{~K}$ membrane for in-vitro and invivo studies.

\section{Octet/ FcRn binding kinetics}

Biolayer interferometry on an Octet Red96 system (PALL/ForteBio) was used to characterize the binding kinetics of the GLP-1-PEG-albumin conjugates. Biotinylated mouse and human FcRn $(m \mathrm{FcRn}$ and $h \mathrm{FcRn})$ were purchased from Immunitrack, Denmark, and immobilized on streptavidin coated biosensors (PALL/ForteBio) in PBS pH 7.4 supplemented with 0.01\% Tween-20.

The sensors were pre-blocked to minimize non-specific binding by 5 min soaking in rHSA diluted to $0.5 \mathrm{mg} / \mathrm{mL}$ in $25 \mathrm{mM}$ Na-acetate, $25 \mathrm{mM} \mathrm{NaH} \mathrm{PO}_{4}, 150 \mathrm{mM} \mathrm{NaCl}, 0.01 \%$ Tween-20 pH 5.5, followed by $5 \mathrm{~min}$. rinse in the same buffer without rHSA, and subsequently in milliQ water. The sensors were prepared for storage by soaking in $15 \%$ sucrose and air drying. 
For kinetic characterization, a 7-step two fold dilution series was prepared in $25 \mathrm{mM}$ Na-acetate, 25 $\mathrm{mM} \mathrm{NaH} 2 \mathrm{PO}_{4}, 150 \mathrm{mM} \mathrm{NaCl}, 0.01 \%$ Tween-20 at $\mathrm{pH} 5.5$ starting at $100 \mu \mathrm{g} / \mathrm{mL}$ for $\mathrm{pH} 5.5$ except for NB-albumin and GLP-1-PEG-NB-albumin starting at $400 \mu \mathrm{g} / \mathrm{mL}$. The binding kinetics were performed at $30^{\circ} \mathrm{C}$ with a $120 \mathrm{sec}$. association phase and $300 \mathrm{sec}$. dissociation phase. The sensors were regenerated with PBS pH 7.4 and equilibrated in $25 \mathrm{mM} \mathrm{Na}$-acetate, $25 \mathrm{mM} \mathrm{NaH}_{2} \mathrm{PO}_{4}, 150 \mathrm{mM}$ $\mathrm{NaCl}, 0.01 \%$ Tween-20 at the specified $\mathrm{pH}$ between the different samples. All data were referenced with FcRn-streptavidin sensors in buffer without rHSA or GLP-1 albumin conjugates. Data analysis was performed using the Octet data analysis software ver. 8.0 (PALL/ForteBio) using curve fitting to a 1-1 model for estimation of kinetic parameters. For the variants with a fast off-rate only the first 30 sec of the dissociation phase were included for curve fitting to minimize the contribution of unspecific binding to the sensors.

\section{SAXS solution structure determination}

SAXS measurements were performed at the MAX IV laboratories at beamline I911-SAXS, Lund, Sweden ${ }^{43}$. The sample detector distance and the direct beam position were calibrated using silver behenate. Parameters are listed in Table S2a. Measurements on pure water were used to get the data on an absolute scale. Buffers were measured before and after each sample and averaged before subtraction. The sample size was approximately $50 \mu \mathrm{L}$ using an automated flow cell. Measurements were performed on a series of samples as outlined in Table S2b.

All calibrations and corrections of the SAXS data were done using the in-house software Bli911-4 ${ }^{43}$. Buffer averaging and subsequent subtraction prior to data analysis were done in Primus ${ }^{44}$.

The difference between the scattering curves of GLP-1 albumin conjugates and rHSA variants was qualitatively compared by comparing the curves individually by $\chi^{2}$ using the online similarity tool created by the Sibyls group ${ }^{45}$.

The ATSAS program package version $2.4^{46}$ was used for further data treatment and analysis. Evaluation of the Guinier region was performed within Primus. The pair distribution function, $p(r)$, was evaluated using the interactive program GNOM ${ }^{47}$. The flexibility was analysed using the dimensionless Kratky plot ${ }^{48}$ where $\left(q R_{g}\right) 2 I(q) / I(0)$ is displayed as a function of $q R_{g}$, making the plot independent of protein size and intensity scale.

3D crystal structures of HSA exist with and without fatty acids bound. We compared the SAXS measurements of the rHSA variants to the defatted structure (pdbid: $1 \mathrm{AO}^{49}$ ) and a fatty acid bound structure (pdbid: $1 \mathrm{BJ} 5^{50}$ ) using Crysol ${ }^{51}$. The best match was found with pdbid 1AO6, which was used for further modelling. The linker between rHSA and GLP-1 was modelled by 7 glycine residues, approximating the chemical nature of the PEG linker.

Rigid body modelling of the GLP-1-PEG-albumin conjugates with the linker between rHSA (pdbid: $1 \mathrm{AO}^{49}$ ) and GLP-1 (pdbid: 1D0R ${ }^{52}$ ) was done in BUNCH ${ }^{53}$. Due to variations in the models produced by $\mathrm{BUNCH}$, the flexibility of the conjugates was evaluated using the ensemble optimization method (EOM) ${ }^{54,55}$. 


\section{GLP-1 activity assay}

In vitro biological activities of GLP-1, GLP-1-PEG-mal and GLP-1-PEG-WT-albumin conjugates were determined by an agonist-binding assay using $\beta$ TC6 pancreatic tumour cells. Cells were incubated with titrations of test compounds or $10 \mathrm{nM}$ control GLP-1 (7-37) for 10 minutes at room temperature, and cAMP was measured by homogeneous time resolved fluorescence (HTRF) as described in ${ }^{11}$. Results were normalized to control GLP-1 and $\mathrm{EC}_{50}$ values were calculated from fits of dose-response curves (four parameters variable slope).

\section{Pharmacokinetics in NMRI WT mice}

The pharmacokinetic study was approved by the ethical committees at both BioAdvice (Ølstykke, Denmark) and Novozymes A/S. The study was performed at BioAdvice. $5 \mathrm{mg} / \mathrm{kg}$ of GLP-1-PEGWT-albumin, GLP-1-PEG-HB-albumin or WT-albumin were administered intravenously to NMRI mice (female, aged 8-10 weeks, weight between 20 and 22 g, 10 mice/compound, 5 mice/time point). Blood samples were collected from the tail vessel in time intervals of predose $0.5,1,2,4,8,12,24$, 48, 72, 96, 120, 144, 168 and 192 hours. Upon collection, the blood samples were kept at $4^{\circ} \mathrm{C}$ for a maximal duration of 3 hours followed by centrifugation at $14,000 \mathrm{G}$ for $15 \mathrm{~min}$ at $20^{\circ} \mathrm{C}$ and stored at $-80^{\circ} \mathrm{C}$ prior to bioanalysis. Serum concentrations were determined using an AlphaLISA method employing a commercial HSA kit (AL296C, Perkin Elmer, MA, USA) combined with a monoclonal anti-GLP-1 biotinylated monoclonal antibody (Ab121072, Abcam) to detect both albumin and GLP1 moieties simultaneously; for albumin alone, the albumin kit was used. The standard curve on each plate was fitted to a four-parameter nonlinear regression model, and the serum concentrations were calculated at each time point using the dilutions that fell within the linear range of the standard curve. Mean serum concentration profiles were subjected to non-compartmental pharmacokinetic analysis using WinNonLin 6.3. Nominal time points and doses were used, and all data points were equally weighted in the analysis.

\section{RESULTS}

\section{Pharmacology}

The kinetic parameters as determined by Biolayer interferometry are summarized in Table 1 and the sensorgrams are shown in Figure S1. Several things may be noticed. First, an increased binding to FcRn is seen by HB-albumin compared to WT-albumin by a factor of 20 due to an $\sim 10$-fold decrease in $k_{\text {off. }}$. Second, the data show that conjugation of GLP-1 to C34 in any of the variants result in similar $K_{D}, k_{\text {off }}$ and $k_{o n}$. This indicates that neither $h \mathrm{FcRn}$ nor $m \mathrm{FcRn}$ binding is hampered by conjugation. Third, if we compare the human WT-albumin and the mouse albumin, it is clear that the mouse protein binds better to both $h \mathrm{FcRn}$ and $m \mathrm{FcRn}$, similar to what has been observed by others ${ }^{56}$. We found a factor of 10 in difference for $m \mathrm{FcRn}$ and a factor of 3 for $h \mathrm{FcRn}$. In addition, it is clear that human WT-albumin binds much better to $h$ FcRn than to $m$ FcRn $(548.7 \mathrm{nM}$ vs. $4702.0 \mathrm{nM})$. The $K_{D}$ values summarized in Table 1 are in the same range as earlier reported when measured using the Biolayer

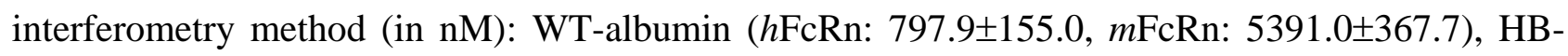


albumin $(h \mathrm{FcRn}: 31.5 \pm 9.8, m \mathrm{FcRn}: 764.3 \pm 17.5)$ and mouse albumin $(h \mathrm{FcRn}: 74.6 \pm 13.4, m \mathrm{FcRn}$ : $314.9 \pm 12.1)^{57}$.

Table 1 Octet Binding kinetics - affinity towards the human and $m$ FcRn receptor

\begin{tabular}{l|cc|c|c|c|c}
\hline & \multicolumn{3}{|c|}{$h$ FcRn } & \multicolumn{3}{c}{$m$ FcRn } \\
\hline & $\begin{array}{c}K_{D} \pm \text { SD } \\
(\mathbf{n M})\end{array}$ & $\begin{array}{c}\boldsymbol{k}_{\text {on }} \pm \text { SD } \\
\left(\mathbf{1 0}^{-3} / \mathbf{M s}\right)\end{array}$ & $\begin{array}{c}\boldsymbol{k}_{\text {off }} \pm \text { SD } \\
\left(\mathbf{1 0}^{3} / \mathbf{s}\right)\end{array}$ & $\begin{array}{c}\boldsymbol{K}_{\boldsymbol{D}} \pm \text { SD } \\
(\mathbf{n M})\end{array}$ & $\begin{array}{c}\boldsymbol{k}_{\text {on }} \pm \text { SD } \\
\left(\mathbf{1 0}^{-3} / \mathbf{M s}\right)\end{array}$ & $\begin{array}{c}\boldsymbol{k}_{\text {off }} \pm \text { SD } \\
(\mathbf{1 0} / \mathbf{s})\end{array}$ \\
\hline WT-albumin & $548.7 \pm 90.2$ & $31.5 \pm 2.8$ & $17.1 \pm 1.4$ & $4702.0 \pm 1096.5$ & $11.7 \pm 3.9$ & $52.0 \pm 9.5$ \\
GLP-1-PEG-WT-albumin & $856.5 \pm 94.9$ & $25.5 \pm 2.8$ & $21.7 \pm 1.4$ & $3506.7 \pm 910.2$ & $11.7 \pm 2.6$ & $39.6 \pm 5.5$ \\
NB-albumin & & Low binding & & \multicolumn{3}{c}{ Very low binding } \\
GLP-1- PEG-NB-albumin & & Vow binding & & Very binding \\
HB-albumin & $25.2 \pm 4.3$ & $35.4 \pm 3.9$ & $0.9 \pm 0.1$ & $1774.0 \pm 299.7$ & $20.1 \pm 3.0$ & $34.9 \pm 1.0$ \\
GLP-1- PEG-HB-albumin & $26.1 \pm 2.7$ & $40.3 \pm 2.1$ & $1.0 \pm 0.1$ & $1324.7 \pm 418.7$ & $21.5 \pm 4.9$ & $27.1 \pm 1.5$ \\
Mouse albumin & $191.6 \pm 31.4$ & $22.6 \pm 1.6$ & $4.3 \pm 0.4$ & $486.2 \pm 125.2$ & $21.3 \pm 4.0$ & $10.1 \pm 0.7$ \\
\hline
\end{tabular}

\section{GLP-1-PEG-albumin conjugates potency and pharmacokinetics}

GLP-1-PEG-WT-albumin potency was investigated and compared to that of unconjugated GLP-1 and of GLP-1-PEG-mal (Figure 1). The in vitro activity of GLP-1 and its conjugated counterparts was measured by generation of cAMP after stimulation of $\beta$ TC6 pancreatic tumour cells. When conjugated to PEG-albumin, the potency of GLP-1 was reduced by 3-4 orders of magnitude, seen by a shift in $\mathrm{EC}_{50}$ from $5.257 \times 10^{-11}$ to $1.730 \times 10^{-7}$ (See table insertion in Figure 1). A smaller decrease in potency was found when GLP-1 was conjugated to PEG-mal alone.

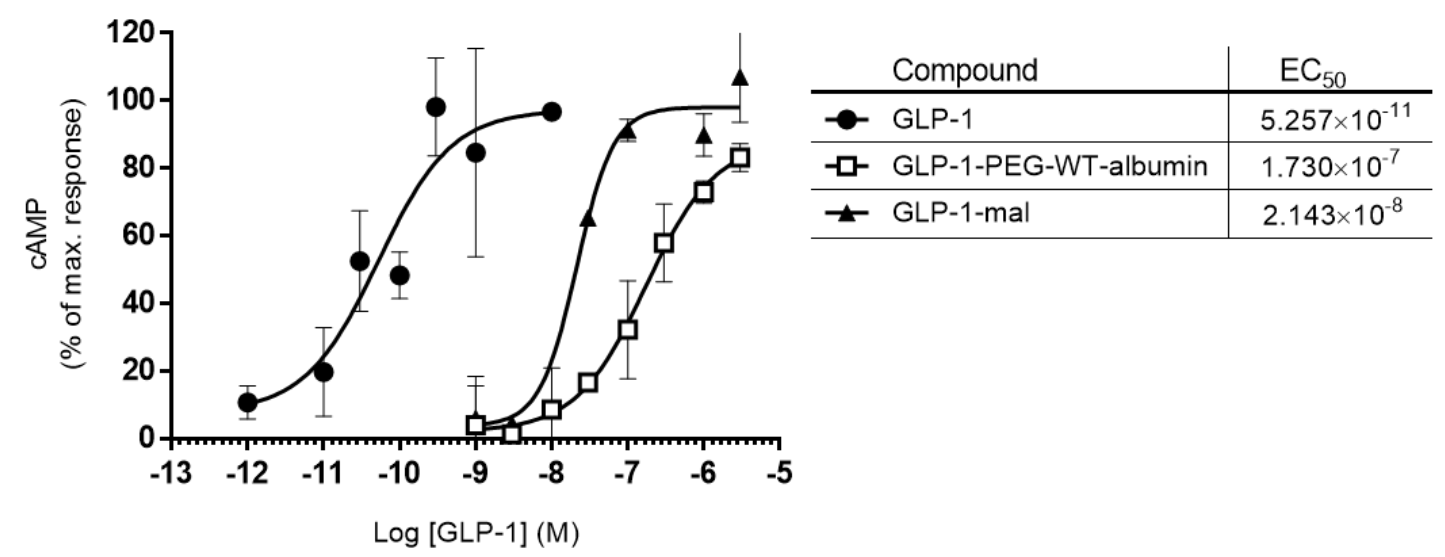

Figure 1 In vitro biological activity of GLP-1, GLP-1-PEG-mal and GLP-1-PEG-WT-albumin in $\beta$ TC6 cells. cAMP response is shown and data represent the means $\pm \mathrm{SD}$ of replicates.

Mouse pharmacokinetics of rHSA alone and GLP-1 linked albumins are shown in Table 2. Reported GLP-1 half-life in mice is approx. 2 min ${ }^{58}$, while the half-life of rHSA is approx. 22 hours ${ }^{39}$ The latter compares well to the half-life found in this study (Table 2). Linking GLP-1 to WT-albumin is shown to extend the half-life of GLP-1 significantly (Figure 2), and the half-life increases from 0.03 hours to 8.5 hours corresponding to a 280 fold increase. Replacing WT-albumin with the high FcRn 
binding affinity variant HB-albumin extends the half-life of GLP-1 330-fold (to 9.9 hours; Table 2). The HB-albumin variant also increases the systemic exposure of the drug (note the increase in AUC for GLP-1-PEG-HB-albumin). These results emphasize the benefits of using rHSA and rHSA variants to improve the pharmacokinetics of receptor agonists such as GLP1.

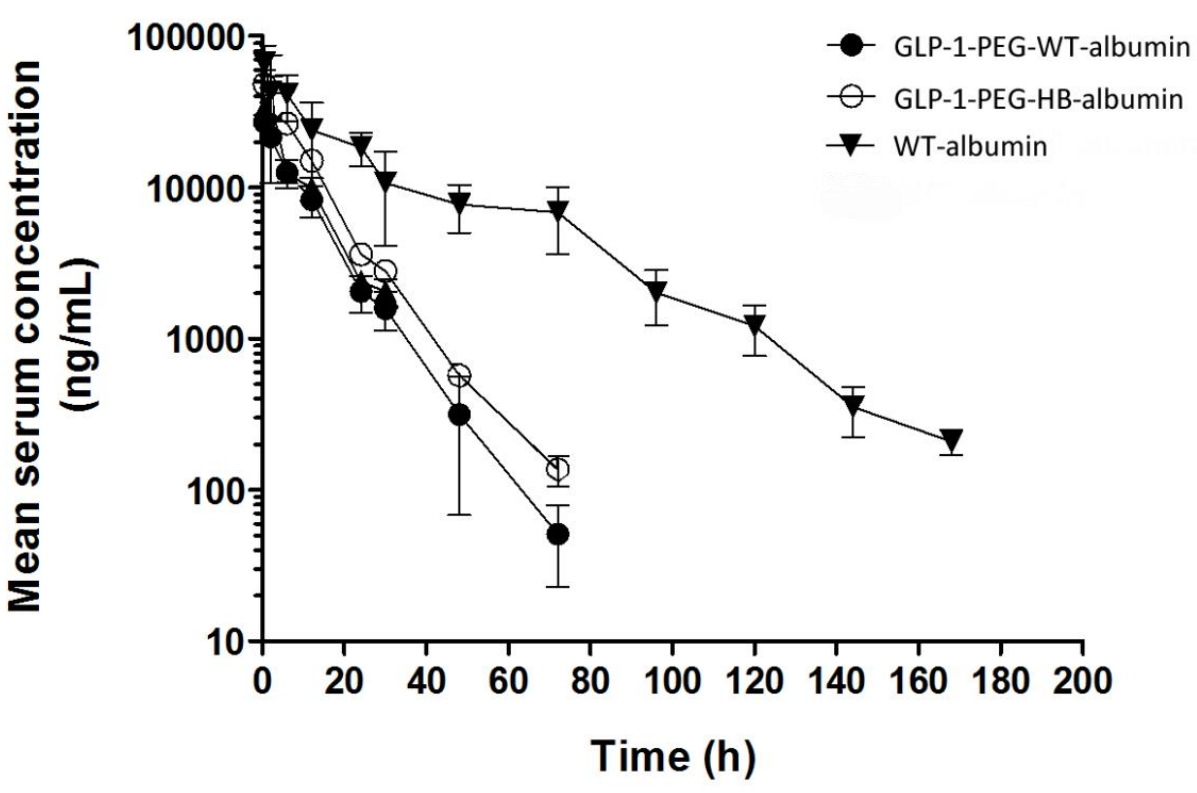

Figure 2 Pharmacokinetic profiles of WT-albumin, GLP-1-PEG-WT-albumin and GLP-1-PEG-HB-albumin in NMRI mice administered $5 \mathrm{mg} / \mathrm{kg}$, i.v. Data are based on ten mice.

Table 2 Pharmacokinetics in Mice after Single IV Administration of $5 \mathrm{mg} \mathrm{rHSA}$ variant/kg. $T_{\max }$ : time to reach maximum serum concentration, $C_{\max }$ : maximum concentration after administration, $A U C_{0-\infty}$ : area under the curve, $t_{1 / 2}$ : elimination half-life, $V_{\mathrm{Z}}$ : volume of distribution, $\mathrm{Cl}$ : clearance; volume of plasma from which a drug is eliminated per unit time.

\begin{tabular}{l|l|l|l|l|l|l}
\hline Compound & $\begin{array}{l}\boldsymbol{T}_{\max } \\
(\mathrm{h})\end{array}$ & $\begin{array}{l}\boldsymbol{C}_{\max } \\
(\mu \mathrm{g} / \mathrm{mL})\end{array}$ & $\begin{array}{l}\mathbf{A U C} \mathbf{C}_{-\infty} \\
(\mathrm{h} \cdot \mu \mathrm{g} / \mathrm{mL})\end{array}$ & $\begin{array}{l}\boldsymbol{t}_{\mathbf{1} / \mathbf{2}} \\
(\mathrm{h})\end{array}$ & $\begin{array}{l}\boldsymbol{V}_{\mathbf{Z}} \\
(\mathrm{mL} / \mathrm{kg})\end{array}$ & $\begin{array}{l}\boldsymbol{C l} \\
\left(\mathrm{mL} \mathrm{kg}^{-1} \cdot \mathrm{h}^{-1}\right)\end{array}$ \\
\hline GLP-1 & - & - & - & $0.03^{58}$ & - & - \\
\hline WT-albumin & 0.5 & 66 & 1481 & 21.5 & 104 & 3.4 \\
\hline GLP-1-PEG-WT-albumin & 0.5 & 27 & 276 & 8.5 & 223 & 18.1 \\
\hline GLP-1-PEG-HB-albumin & 0.5 & 48 & 494 & 9.9 & 143 & 10.1 \\
\hline
\end{tabular}

\section{SAXS}

All scattering profiles are shown in Figure S2 and the data analysis parameters are listed in Table S3. The three rHSA variants have similar scattering curves and the three GLP-1 albumin conjugates have similar scattering curves. This is further verified by the similarity test shown in Figure S3, which also establishes that the GLP-1 albumin conjugates are structurally different from the unconjugated albumins.

All GLP-1-PEG-albumin conjugates have larger radius of gyration $\left(R_{g}\right)$ than the rHSA variants as shown in Table 3. This indicates that the conjugated GLP-1 somewhat protrudes away from the rHSA instead of interacting with the protein surface. This is further verified by the results from the 
dimensionless Kratky plots shown in Figure 3, where GLP-1-PEG-HB-albumin is compared to the HB-albumin variant. The plots show how the conjugate is larger as the maximum of the curve is shifted to higher $q R_{g}$ values.

Table $3 R_{g}$ determined from Guinier analysis using Primus [51].

\begin{tabular}{l|l|l|l|l|l}
\hline $\begin{array}{l}\text { Compound } \\
(\mathbf{1 ~ m g} / \mathbf{m l})\end{array}$ & $\boldsymbol{R}_{\boldsymbol{g}}(\mathbf{n m})$ & $\begin{array}{l}\text { Standard } \\
\text { deviation }\end{array}$ & $\begin{array}{l}\text { Compound } \\
(\mathbf{1 ~ m g / m l})\end{array}$ & $\boldsymbol{R}_{\boldsymbol{g}}(\boldsymbol{n m})$ & $\begin{array}{l}\text { Standard } \\
\text { deviation }\end{array}$ \\
\hline WT-albumin & 2.96 & 0.19 & GLP-1-PEG-WT-albumin & 3.16 & 0.18 \\
\hline NB-albumin & 3.00 & 0.29 & GLP-1-PEG-NB-albumin & 3.19 & 0.18 \\
\hline HB-albumin & 2.98 & 0.18 & GLP-1-PEG-HB-albumin & 3.18 & 0.26 \\
\hline
\end{tabular}

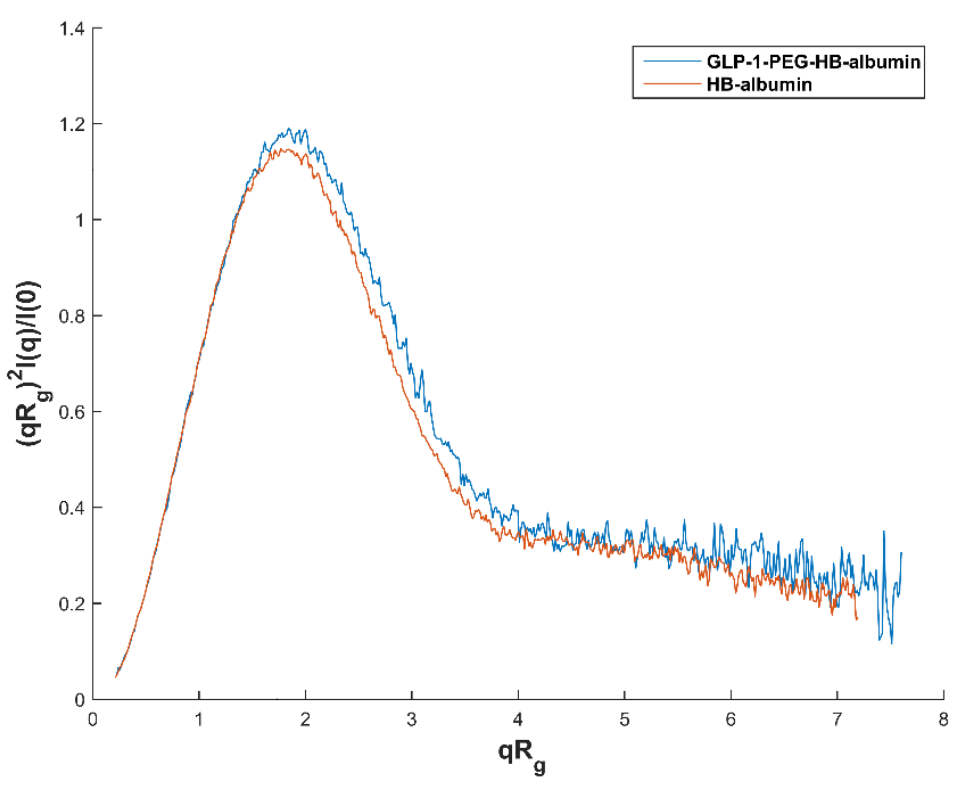

Figure 3 Dimensionless Kratky plot of GLP-1-PEG-HB-albumin compared to HB-albumin

The structure of GLP-1 was taken as an ensemble representative from the pdb entry 1D0R. This structure of human GLP-1 is an NMR structure determined at $\mathrm{pH} 2.5$, while a crystal structure in complex with the extracellular part of the GLP-1R (pdbid: 3IOL) is at $\mathrm{pH}$ 6.9. These two structures show very similar secondary structure of GLP-1. Based on this there is no reason to believe that GLP1 should change structure at $\mathrm{pH}$ 7.4. $\mathrm{BUNCH}^{53}$ gave models with $\chi^{2}$ values in the range from 3.48 3.88 for the GLP-1-PEG-HB-albumin models. Results from the 10 independent BUNCH simulations from the GLP-1-PEG-HB-albumin are shown in Figure 4. The NB and the WT variants gave similar results. 
Domain III

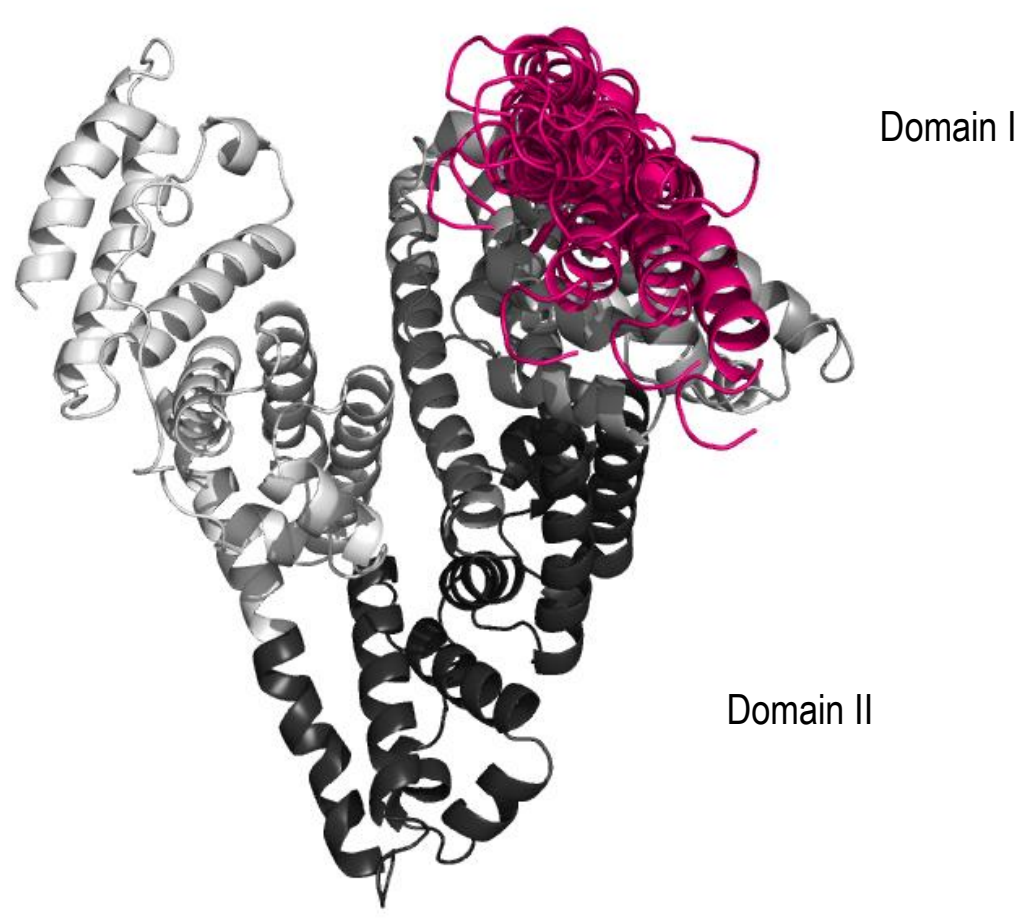

Figure 4 GLP-1-PEG-HB-albumin shown in gray (domain I: medium gray, domain II: dark gray, domain III: light gray) and the conjugated GLP-1s are shown in pink as 10 representative structures.

Due to the semi-flexible nature of the GLP-1 albumin conjugates observed from BUNCH and the dimensionless Kratky plot, modelling was performed again but this time with the Ensemble Optimization Method (EOM) ${ }^{54,55}$. EOM was run in two different ways: One with the structure of GLP-1 set as a helix, i.e. the same PDB structure as above, and a flexible linker and one where the entire GLP-1 and the linker are flexible, though with geometry optimized backbone angles. The results are shown in Figure S4, which show that the helical structure of GLP-1 is a good approximation, as the $R_{g}$ and $D_{\max }$ distributions are very similar between the two methods, and the $\chi^{2}$ values were 1.150 and 1.145 respectively for the GLP-1-PEG-albumin conjugates, confirming the flexibility of the GLP-1 position.

\section{DISCUSSION}

The rHSA variants were previously shown to have different affinities for the $\mathrm{FcRn}^{39,40}$, which was confirmed by the $K_{D}$ data in Table 1 showing increased binding for HB-albumin and reduced binding for NB-albumin compared to WT-albumin. Two crystal structures exist of the FcRn:rHSA complex. A complex of a quadruple rHSA variant V418M/T420A/E505G/V547A in complex with $h$ FcRn (pdbid: $4 \mathrm{~K}_{71^{59}}$ ) and a complex between WT-rHSA and $h$ FcRn (pdbid: $4 \mathrm{NOF}{ }^{60}$ ). The pH dependent binding of HSA to the FcRn facilitates the recycling of HSA. HSA undergoes conformational changes upon binding, which is a major movement of domain III and a smaller movement of domain I with respect to domain II. The domain positions of HSA are indicated in Figure 7. It is discussed if the $\mathrm{pH}$ dependent binding is governed primarily by FcRn H161, which is the only histidine residue observed in the interface between HSA and $h \mathrm{FcRn}{ }^{60}$ or if it is governed by a number of conserved histidine 
residues in FcRn and $\mathrm{HSA}^{40}$ Furthermore, it is observed that two conserved tryptophan residues, W53 and W59 in the $h$ FcRn $\alpha$-chain, are deeply docked into the fatty acid binding sites in HSA suggesting that binding of fatty acids to HSA hampers recycling ${ }^{59}$ and that the interface between HSA and $h$ FcRn mainly is governed by hydrophobic interactions.

The SAXS experiments performed at $\mathrm{pH} 7.4$ confirm that the solution structure of the two variants (NB-albumin and HB-albumin) and the WT-albumin are indistinguishable from each other as the scattering curves are identical (as shown in Figures S2 and S3).

The GLP-1-PEG-albumin conjugates also had similar scattering curves and could all be modelled using GLP-1 protruding from the surface of rHSA with the rHSA conformation found in the defatted structure. Flexibility of the linker was confirmed by comparing BUNCH and EOM results, though limited to a cone area of an approximate diameter of $40 \AA$, as may be deduced from Figure 4 .

Both the NB-albumin and the HB-albumin have amino acids changed on the surface of domain III in rHSA. The analysis of the structural impact of the variants is hampered by the fact that differences are observed in the two complex structures (pdbids: 4N0F or 4K71) in exactly this area of the structure: The NB-albumin K500A has a lysine changed to an alanine on the surface of domain III, involved in the FcRn binding. The K500 in the native structure of the rHSA-FcRn complex (pdbid: 4NOF; Figure 5, (A)), is making an intramolecular salt bridge to rHSA E531. This salt bridge is not present in the fatty acid bound HSA structure (pdbid: 1BJ5; Figure 5 (B)) and could therefore be important for the domain movement, facilitating FcRn binding. Furthermore, rHSA K500 also forms a salt bridge with FcRn $\alpha$ E46. These salt bridges are in the proximity of the pocket where the FcRn W53 is binding. It is plausible that breaking these salt bridges will make it less favourable for W53 to bind, affecting complex formation (see Figure 5).

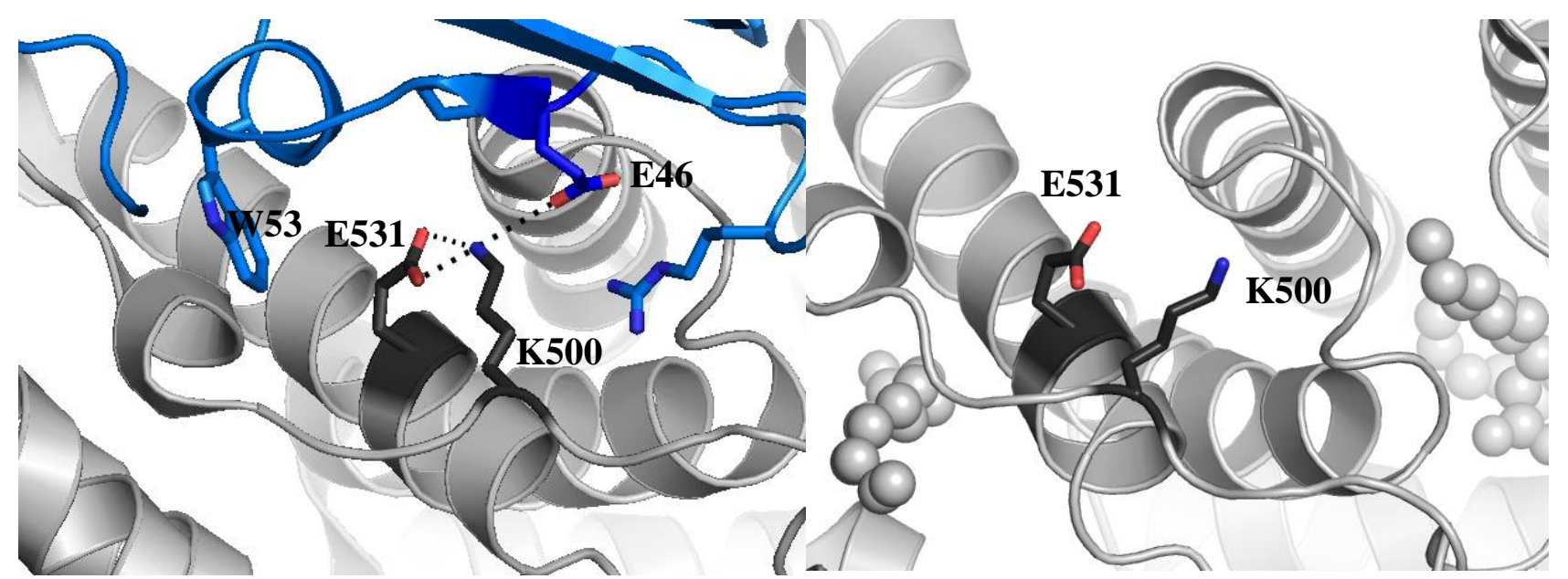

(A)

(B)

Figure 5 rHSA K500, rHSA E531 (black) and FcRn $\alpha$ E46 (dark blue) showing electrostatic interaction in the rHSA-FcRn structure (A): pdbid: 4N0F . rHSA E531 and rHSA K500 do not interact in fatty acid bound rHSA (B): (pdbid: 1BJ5) The gray spheres are myristic acids bound to rHSA. Color code: Gray: rHSA, Blue: FcRn $\alpha$ chain. 
When speculating about binding to FcRn there is no reason to believe that the mechanism for the HB-albumin differs from that found for HSA. The $\mathrm{pH}$ dependent binding is believed to be triggered by protonation of one or more histidine residues. This should still be possible in the investigated K573P HB variant. The observed difference in binding is a slightly improved association rate and a slower dissociation rate as indicated by $k_{\text {on }}$ and $k_{\text {off }}$ in Table 1 , with retained $\mathrm{pH}$ dependent binding as observed by Petersen et al. ${ }^{61}$. The HB variant has been changed on the surface of domain III where it interacts with the FcRn $\beta 2 \mathrm{~m}$ chain. The primates are unique in having a lysine at position $573-$ the most common amino acid at this position (and also in mouse) is a proline ${ }^{59}$. Consulting the two available crystal structures of rHSA complexed with FcRn (pdbid:4K71 and pdbid:4N0F) shows that K573 is interacting with S20 and E69 in pdb structure 4K71 (Figure 6 (B)) but not in 4N0F (Figure 6 (A)) where it is bent away from FcRn F22 in the $\beta 2 \mathrm{~m}$ chain. The global binding mechanism behind the effect of changing K573 is therefore less clear. If steric hindrance with F22 is minimized, it may be rationalized that by changing it to a smaller side chain, binding would be improved. It is also plausible that the proline substitution promotes formation of the hydrophobic interface between HSA and FcRn and maintains the small kink in the HSA helix present at this position.

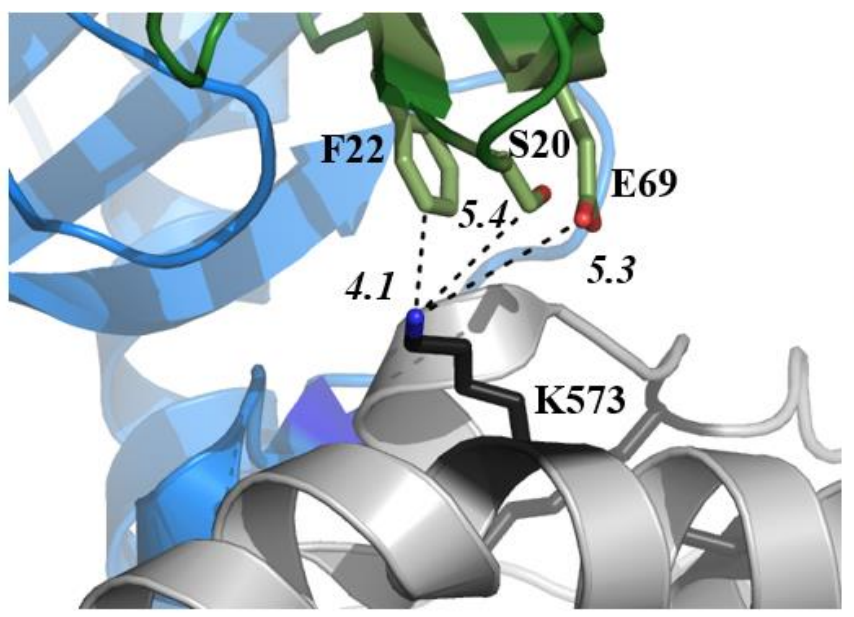

(A)

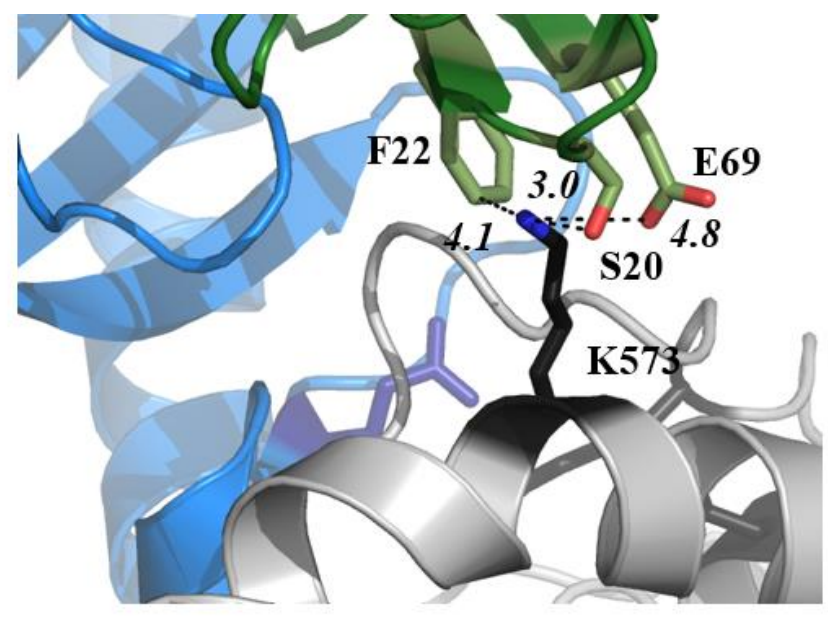

(B)

Figure 6 Interaction of K573 (black) with S20, F22 and E69 from the $\beta 2 \mathrm{~m}$ chain of FcRn. (A): pdbid: 4N0F , (B): pdbid: 4K71 . Color code: Gray: rHSA, Green: FcRn $\beta 2 \mathrm{~m}$ chain and Blue: FcRn $\alpha$ chain. Distances $(\AA)$ are shown in italic and measured in Pymol.

Conjugation of GLP-1 to rHSA had no effect on the FcRn interaction per se. FcRn interactions were shown to be unchanged in-vitro and this finding was further confirmed in-vivo. GLP-1-PEG-HBalbumin showed improved PK compared to GLP-1-PEG-WT-albumin indicating that FcRn-HSA interactions are preserved and can be modulated despite the payload. The overall decrease in half-life (and in this respect the increase in clearance) seen for the GLP-1 albumin conjugates compared to WT-albumin is therefore not caused by FcRn binding impairment. Disposition of GLP-1 and its functional interaction with its receptor, GLP-1R, alter the pharmacokinetics of the conjugates. The bioanalysis of the GLP-1 albumin conjugates was initially performed by employing antibodies against HSA and GLP-1 simultaneously. To confirm that the conjugates are cleared as one molecule, hence GLP-1 does not come off the rHSA while in circulation, we performed bioanalysis of total HSA 
content using only HSA antibodies. Both GLP-1 albumin conjugates as well as HSA plasma curves overlayed (data not shown). These results confirmed the conjugates remain intact and the clearance mechanisms metabolise the whole molecule simultaneously. As reported for GLP1 and GLP1 agonists, the results suggest the conjugates are cleared via receptor-mediated endocytosis by GLP$1 \mathrm{R}{ }^{62}$. In-vivo studies will be relevant to confirm the efficacy of GLP-1 while conjugated to rHSA and evaluate the full effect on half-life extension.

It is worth highlighting that these PK studies were performed in mice and therefore limited by crossspecies differences. Cross-species differences constitute a major limitation in pre-clinical development particularly upon distinct receptor binding kinetics. It has been recognized that caution should be taken when using rodent models to study the pharmacokinetics of albumin conjugated drugs 56. This is also seen in the present results, where the affinity of the mouse albumin against the $m$ FcRn is significantly higher than any of the rHSA variants tested (Table 1 ). $K_{D}$ for mouse albumin is 2-10 times lower than those determined for the rHSA variants. and the concentration of the tested compounds is approximately 200-fold lower than the endogenous concentration at the time of the onset ${ }^{63}$. For this reason significant competition between endogenous mouse albumin and rHSA variants is expected. This translates to the minor improvement achieved for the engineered HBalbumin against the mouse receptor, i.e. 2-3 fold when compared to the 25 -fold improvement against the human receptor $\left(K_{D}\right.$, Table 1). Despite the marginal improvements in FcRn binding affinity seen for the GLP-1-PEG-HB-albumin variant, this variant still outperformed its WT counterpart in-vivo (Table 2). The GLP-1-PEG-HB-albumin showed a slower clearance from plasma leading to $80 \%$ larger exposure and approximately 1.2-fold longer half-life. Based on in-vitro binding kinetics and non-human primate studies evaluating the pharmacokinetics of engineered rHSA variants ${ }^{39}$, we expect the improvement seen here for the GLP-1-PEG-HB-albumin to render a much more significant pharmacokinetic improvement in primates.

In Figure 7, the structure of rHSA in complex with the extracellular domain of the FcRn (pdbid: 4NOF), has been superimposed with a representative model of the GLP-1-PEG-HB-albumin derived from SAXS data using BUNCH (seen in Figure 4). The conjugation of GLP-1 to C34 is seen to be in close proximity to the interface area between HSA and FcRn. Apparently, it - even if it is close to the FcRn - does not sterically hinder the binding of rHSA to the FcRn consistent with the data in Table 1. Here, it is observed that the affinity and thus the ability to bind to the FcRn seems unchanged upon conjugation, indicating that the ability to recycle is retained. 


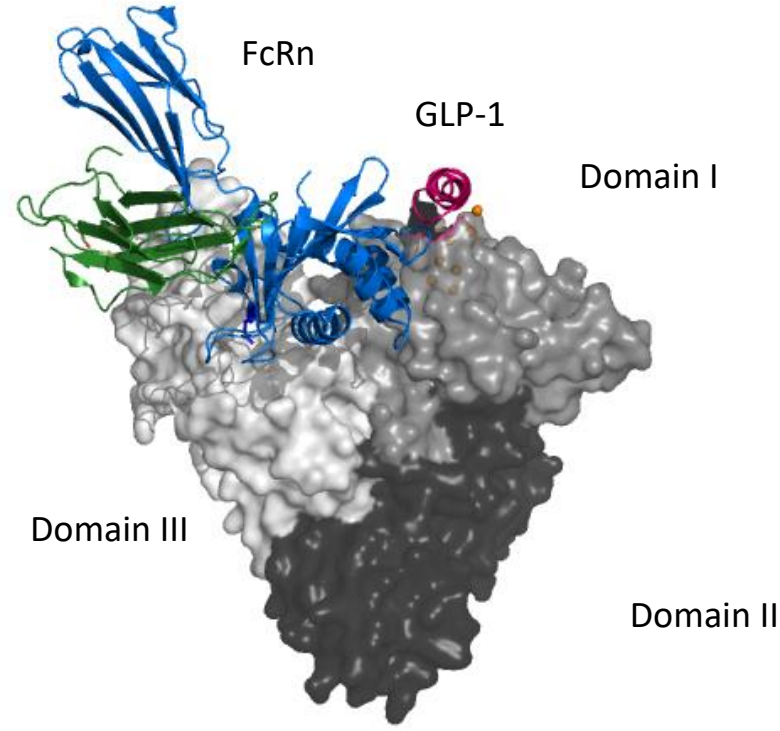

(A)

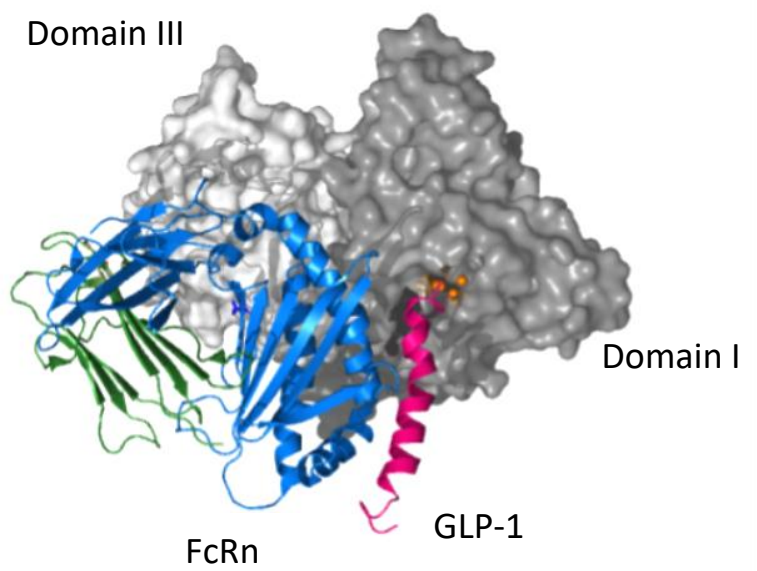

(B)

Figure 7 (A): The structure of rHSA in complex with the extracellular part of FcRn (pdbid: 4N0F) superimposed on a SAXS-based BUNCH model of GLP-1-PEG-HB-albumin. HSA is displayed in gray (domain I: medium gray, domain II: dark gray, domain III: light gray), FcRn $\alpha$ in blue and $\beta-2 \mathrm{~m}$ in green and the conjugated GLP-1 in pink. (B): Turned and seen from the top.

In contrast to this, Petersen et al. ${ }^{61}$ examined the effect on the binding affinity of PEGylated rHSA to FcRn. PEG of sizes 5, 10 and $30 \mathrm{kDa}$ were conjugated to C34 of rHSA. The authors proposed that steric hindrance could be the reason for the observed decreased affinity of the GLP-1 albumin conjugates compared to rHSA.

While the interaction of FcRn with HSA is important for half-life extension of GLP-1, the efficacy is highly dependent on GLP-1 interactions with GLP-1R. From the biological activity assay it was observed that PEG-mal-conjugation to GLP-1 alone lowered the potency by three orders of magnitude for the GLP-1R (Figure 1), and that additionally conjugating rHSA decreased the potency by four orders of magnitude in total. In Figure 8 (A), the structure of GLP-1 in complex with the extracellular part of the GLP-1R (pdbid: 3IOL) has been superimposed with a model of the GLP-1-PEG-HBalbumin. Here, it is seen that the GLP-1 albumin conjugate may bind to the extracellular part of GLP1R. The full length crystal structure of GLP-1R in complex with a peptide agonist ${ }^{38}$ was used to visualize the binding between GLP-1-PEG-albumin and full-length GLP-1R (Figure 8 (B)). Realizing the limitations of this model, it is apparent that albumin within the GLP-1-PEG-albumin conjugate may impact the activity of the GLP-1 moiety, possibly by colliding with the cell membrane, resulting in the lower potency observed for conjugated GLP-1 compared to WT GLP-1. Selis et al. ${ }^{64}$ observed a decrease in potency of 2-3 orders of magnitude for a number of PEGylated GLP-1 variants. These variants have been PEGylated at GLP-1 positions 11, 23 or 30, which may explain the somewhat smaller decrease in potency compared to our GLP-1-PEG-albumins, which are modified in the Cterminal position 36. This highlights that optimizing the conjugation position is required. 
Furthermore, the GLP-1 potency may be regained by changing the conjugation site on rHSA. Our SAXS based models may in this way serve as a valuable source of inspiration for such a design.

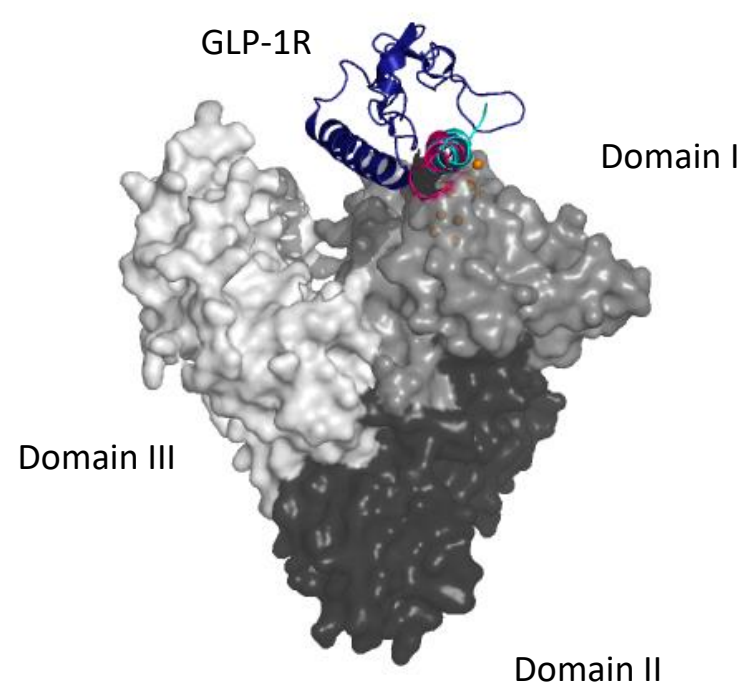

(A)

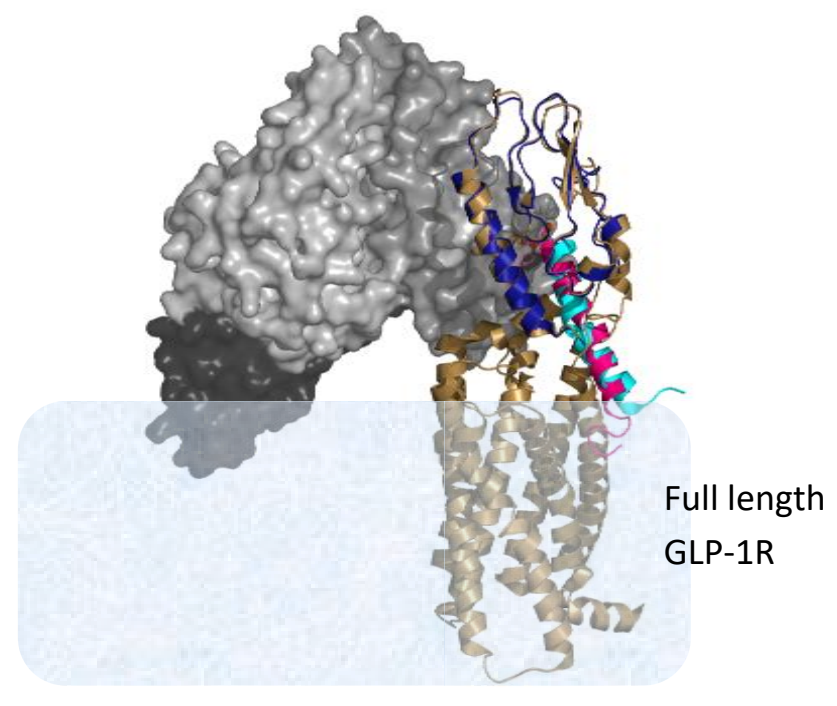

(B)

Figure 8 (A): The structure of GLP-1 (turquoise) in complex with the extracellular part of the GLP-1 receptor (blue), (pdbid: 3IOL) superimposed on a SAXS-based BUNCH model of GLP-1-PEG-HB-albumin. The conjugated GLP-1 is shown in pink, and HSA is displayed in gray (domain I: medium gray, domain II: dark gray, domain III: light gray). (B): A rotated version of (A), but with the full-length GLP-1R crystal structure s $^{38}$ (in bronze) (pdbid: 5NX2) superimposed, and a membrane is indicated as a light blue shadow.

\section{CONCLUSION}

We have studied the effect of conjugating GLP-1 to C34 of WT-, NB- and HB-albumin. The solution structures were determined using SAXS and the results were compared with FcRn binding kinetics, the GLP-1R agonist activity in $\beta$ TC6 pancreatic tumour cells and the pharmacokinetics in mice. Based on the structure of the GLP-1 albumin conjugates we could model the molecular interactions and explain the experimental observations.

FcRn binding kinetics showed that conjugation of GLP-1 to C34 has limited effect on the in-vitro binding to FcRn. In contrast to this the GLP-1R agonist activity in $\beta$ TC6 cells was decreased by 3-4 orders of magnitude. Similarly, from our studies of PK in NMRI mice we find an increase in half-life of the GLP-1-PEG-albumins compared to GLP-1. Both the unaltered binding to FcRn and the decrease in potency are confirmed by the molecular models derived from the SAXS data, which show that the GLP-1 protrudes out from the rHSA surface with some degree of flexibility. These results show that studying the solution structure using SAXS can be valuable in guiding us to engineer drug conjugation, while in the same time maintaining the integrity of the HSA and its interaction with FcRn. 


\section{ACKNOWLEDGEMENTS}

The MAXIV synchrotron and the I911-SAXS beamline crew are acknowledged for beam-time and support during data-collection. The research presented has received funding from BioStruct-X and DANSCATT (the Danish agency and for Science, Technology and Innovation).

\section{REFERENCES}

(1) Federation, I. D. (2015) International Diabetes Atlas (David Cavan, J. da R. F., Lydia Makaroff, K. O., and Webber, S., Eds.) 7th ed. Brussels, Belgium.

(2) Meier, J. J. (2012) GLP-1 receptor agonists for individualized treatment of type 2 diabetes mellitus. Nat. Rev. Endocrinol. 8, 728-742.

(3) Orskov, C., Wettergren, A., and Holst, J. J. (1993) Biological effects and metabolic rates of glucagonlike peptide-1 7-36 amide and glucagonlike peptide-1 7-37 in healthy subjects are indistinguishable. Diabetes 42, 658-661.

(4) Holst, J. J., and Gromada, J. (2004) Role of incretin hormones in the regulation of insulin secretion in diabetic and nondiabetic humans. Am. J. Physiol. Endocrinol. Metab. 287, E199-206.

(5) Vilsbøll, T., and Holst, J. J. (2004) Incretins, insulin secretion and Type 2 diabetes mellitus. Diabetologia 47, $357-$ 366 .

(6) Hassan, M., Eskilsson, A., Nilsson, C., Jonsson, C., Jacobsson, H., Refai, E., Larsson, S., and Efendic, S. (1999) In vivo dynamic distribution of 131I-glucagon-like peptide-1 (7-36) amide in the rat studied by gamma camera. Nucl. Med. Biol. 26, 413-420.

(7) Mentlein, R., Gallwitz, B., and Schmidt, W. E. (1993) Dipeptidyl-peptidase IV hydrolyses gastric inhibitory polypeptide, glucagon-like peptide-1(7-36)amide, peptide histidine methionine and is responsible for their degradation in human serum. Eur. J. Biochem. 214, 829-835.

(8) Meier, J. J., Nauck, M. A., Kranz, D., Holst, J. J., Deacon, C. F., Gaeckler, D., Schmidt, W. E., and Gallwitz, B. (2004) Secretion, Degradation, and Elimination of Glucagon-Like Peptide 1 and Gastric Inhibitory Polypeptide in Patients with Chronic Renal Insufficiency and Healthy Control Subjects. Diabetes 53, 654-662.

(9) Kieffer, T. J., McIntosh, C. H., and Pederson, R. A. (1995) Degradation of glucose-dependent insulinotropic polypeptide and truncated glucagon-like peptide 1 in vitro and in vivo by dipeptidyl peptidase IV. Endocrinology 136, 3585-96.

(10) Deacon, CF; Johnsen, AH; Holst, J. (1995) Degradation of glucagon-like peptide-1 by human plasma in-vitro yields an n-terminally truncated peptide that is a major endogenous metabolite in-vivo. J. Clin. Endocrinol. Metab. 80, 952-957.

(11) Zander, M., Madsbad, S., Madsen, J. L., and Holst, J. J. (2002) Effect of 6-week course of glucagon-like peptide 1 on glycaemic control, insulin sensitivity, and beta-cell function in type 2 diabetes : a parallel-group study. Lancet 359, $824-830$.

(12) Kolterman, O. G., Buse, J. B., Fineman, M. S., Gaines, E., Heintz, S., Bicsak, T. A., Taylor, K., Kim, D., Aisporna, M., Wang, Y., and Baron, A. D. (2003) Synthetic exendin-4 (exenatide) significantly reduces postprandial and fasting plasma glucose in subjects with type 2 diabetes. J. Clin. Endocrinol. Metab. 88, 3082-9.

(13) Werner, U., Haschke, G., Herling, A. W., and Kramer, W. (2010) Pharmacological profile of lixisenatide: A new GLP-1 receptor agonist for the treatment of type 2 diabetes. Regul. Pept. 164, 58-64.

(14) Frederiksen, T. M., Sønderby, P., Ryberg, L. A., Harris, P., Bukrinski, J. T., Scharff-Poulsen, A. M., Elf-Lind, M. N., and Peters, G. H. (2015) Oligomerization of a Glucagon-like Peptide 1 Analog: Bridging Experiment and Simulations. Biophys. J. 109, 1202-1213. 
(15) Knudsen, L. B., Nielsen, P. F., Huusfeldt, P. O., Johansen, N. L., Madsen, K., Pedersen, F. Z., Thøgersen, H., Wilken, M., and Agers $\varnothing$, H. (2000) Potent derivatives of glucagon-like peptide-1 with pharmacokinetic properties suitable for once daily administration. J. Med. Chem. 43, 1664-9.

(16) Mayer, John P., Barrington, Philip, Brenner, Martin, Chadwell, Fred, Chen, Y. (2012) Optimization of a longacting PEGylated GLP-1 agonist LY242875, in 244th ACS National Meeting \& Exposition, p 214. Philadelphia.

(17) Schellenberger, V., Wang, C.-W., Geething, N. C., Spink, B. J., Campbell, A., To, W., Scholle, M. D., Yin, Y., Yao, Y., Bogin, O., Cleland, J. L., Silverman, J., and Stemmer, W. P. C. (2009) A recombinant polypeptide extends the in vivo half-life of peptides and proteins in a tunable manner. Nat. Biotechnol. 27, 1186-1190.

(18) Huang, C. (2009) Receptor-Fc fusion therapeutics, traps, and MIMETIBODYTM technology. Curr. Opin. Biotechnol. 20, 692-699.

(19) Tuan Giam Chuang, V., Kragh-Hansen, U., and Otagiri, M. (2002) Pharmaceutical Strategies Utilizing Recombinant Human Serum Albumin. Pharm. Res. 19, 569-577.

(20) Chaudhury, C., Brooks, C. L., Carter, D. C., Robinson, J. M., and Anderson, C. L. (2006) Albumin binding to FcRn: Distinct from the FcRn-IgG interaction. Biochemistry 45, 4983-4990.

(21) Chaudhury, C., Mehnaz, S., Robinson, J. M., Hayton, W. L., Pearl, D. K., Roopenian, D. C., and Anderson, C. L. (2003) The Major Histocompatibility Complex - related Fc Receptor for IgG ( FcRn ) Binds Albumin and Prolongs Its Lifespan 197.

(22) Andersen, J. T., Qian, J. D., and Sandlie, I. (2006) The conserved histidine 166 residue of the human neonatal Fc receptor heavy chain is critical for the pH-dependent binding to albumin. Eur. J. Immunol. 36, 3044-3051.

(23) Simister, N. E., and Mostov, K. E. (1989) An Fc receptor structurally related to MHC class I antigens. Nature.

(24) Junghans, R. P., and Anderson, C. L. (1996) The protection receptor for IgG catabolism is the beta2microglobulin-containing neonatal intestinal transport receptor. Proc. Natl. Acad. Sci. U. S. A. 93, 5512-6.

(25) Ghetie, V., and ; Hubbard, JG; Kim, JK; Tsen, MF; Lee, YF; Ward, E. (1996) Abnormally short serum half-lives of $\mathrm{IgG}$ in beta 2-microglobulin-deficient mice. Eur. J. Immunol. 26, 690-696.

(26) Ward, E. S., and Ober, R. J. (2009) Multitasking by Exploitation of Intracellular Transport Functions. Adv. Immunol. 103, 77-115.

(27) Sleep, D. (2015) Albumin and its application in drug delivery. Expert Opin. Drug Deliv. 12, $793-812$.

(28) Matthews, J. E., Stewart, M. W., De Boever, E. H., Dobbins, R. L., Hodge, R. J., Walker, S. E., Holland, M. C., Bush, M. A., and Albiglutide Study, G. (2008) Pharmacodynamics, pharmacokinetics, safety, and tolerability of albiglutide, a long-acting glucagon-like peptide-1 mimetic, in patients with type 2 diabetes. J. Clin. Endocrinol. Metab. 93, 4810-4817.

(29) Bush M.A., Matthews J.E., De Boever E.H., Dobbins R.L., Hodge R.J., Holland M.C., Gutierrez M, S. M. W. (2009) Safety, tolerability, pharmacodynamics and pharmacokineticsof albiglutide, a long-acting glucagon-like peptide$1 \mathrm{~m}$ imetic,in healthy subjects. Diabetes, Obes. Metab. 11, 498-505.

(30) Guivarc'h, PH; Castaigne, JP; Gagnon, C; Peslherbe, L; Dreyfus, JH; Drucker, D. (2004) CJC-1131, a long acting GLP-1 analog safely normalizes post-prandial glucose excursion and fasting glycemia in type 2 diabetes mellitus. Diabetes 53, A127.

(31) Lau, J., Bloch, P., Schäffer, L., Pettersson, I., Spetzler, J., Kofoed, J., Madsen, K., Knudsen, L. B., McGuire, J., Steensgaard, D. B., Strauss, H. M., Gram, D. X., Knudsen, S. M., Nielsen, F. S., Thygesen, P., Reedtz-Runge, S., and Kruse, T. (2015) Discovery of the Once-Weekly Glucagon-Like Peptide-1 (GLP-1) Analogue Semaglutide. J. Med. Chem. 58, 7370-7380.

(32) Lau, J., Bloch, P., Schäffer, L., Pettersson, I., Spetzler, J., Kofoed, J., Madsen, K., Knudsen, L. B., McGuire, J., Steensgaard, D. B., Strauss, H. M., Gram, D. X., Knudsen, S. M., Nielsen, F. S., Thygesen, P., Reedtz-Runge, S., and 
Kruse, T. (2015) Discovery of the Once-Weekly Glucagon-Like Peptide-1 (GLP-1) Analogue Semaglutide. J. Med. Chem. 58, 7370-7380.

(33) Chang, X., Keller, D., Bjørn, S., and Led, J. J. (2001) Structure and folding of glucagon-like peptide-1-(7-36)amide in aqueous trifluoroethanol studied by NMR spectroscopy. Magn. Reson. Chem. 39, 477-483.

(34) Runge, S., Thøgersen, H., Madsen, K., Lau, J., and Rudolph, R. (2008) Crystal structure of the ligand-bound glucagon-like peptide-1 receptor extracellular domain. J. Biol. Chem. 283, 11340-11347.

(35) Underwood, C. R., Garibay, P., Knudsen, L. B., Hastrup, S., Peters, G. H., Rudolph, R., and Reedtz-Runge, S. (2010) Crystal structure of glucagon-like peptide-1 in complex with the extracellular domain of the glucagon-like peptide-1 receptor. J. Biol. Chem. 285, 723-730.

(36) Hoare, S. R. J. (2005) Mechanisms of peptide and nonpeptide ligand binding to Class B G-protein-coupled receptors. Drug Discov. Today 10, 417-427.

(37) Thorens, B. (1992) Expression cloning of the pancreatic J8 cell receptor for the gluco-incretin hormone glucagonlike peptide 1. Proc. Nati. Acad. Sci. USA Nati. 89, 8641-8645.

(38) Jazayeri, A., Rappas, M., Brown, A. J. H., Kean, J., Errey, J. C., Robertson, N. J., Fiez-Vandal, C., Andrews, S. P., Congreve, M., Bortolato, A., Mason, J. S., Baig, A. H., Teobald, I., Dor?, A. S., Weir, M., Cooke, R. M., and Marshall, F. H. (2017) Crystal structure of the GLP-1 receptor bound to a peptide agonist. Nature 546, 254-258.

(39) Andersen, J. T., Dalhus, B., Viuff, D., Ravn, B. T., Gunnarsen, K. S., Plumridge, A., Bunting, K., Antunes, F., Williamson, R., Athwal, S., Allan, E., Evans, L., Bjørås, M., Kjærulff, S., Sleep, D., Sandlie, I., and Cameron, J. (2014) Extending serum half-life of albumin by engineering neonatal Fc receptor (FcRn) binding. J. Biol. Chem. 289, 1349213502.

(40) Andersen, J. T., Dalhus, B., Cameron, J., Daba, M. B., Plumridge, A., Evans, L., Brennan, S. O., Gunnarsen, K. S., Bjørås, M., Sleep, D., and Sandlie, I. (2012) Structure-based mutagenesis reveals the albumin-binding site of the neonatal Fc receptor. Nat. Commun. 3, 610.

(41) Li, Z., Leung, W., Yon, A., Nguyen, J., Perez, V. C., Vu, J., Giang, W., Luong, L. T., Phan, T., Salazar, K. A., Gomez, S. R., Au, C., Xiang, F., Thomas, D. W., Franz, A. H., Lin-Cereghino, J., and Lin-Cereghino, G. P. (2010) Secretion and proteolysis of heterologous proteins fused to the Escherichia coli maltose binding protein in Pichia pastoris. Protein Expr. Purif.

(42) Smith, M. E. B., Caspersen, M. B., Robinson, E., Morais, M., Maruani, A., Nunes, J. P. M., Nicholls, K., Saxton, M. J., Caddick, S., Baker, J. R., and Chudasama, V. (2015) A platform for efficient, thiol-stable conjugation to albumin's native single accessible cysteine. Org. Biomol. Chem. 13, 7946-7949.

(43) Labrador, A., Cerenius, Y., Svensson, C., Theodor, K., and Plivelic, T. (2013) The yellow mini-hutch for SAXS experiments at MAX IV Laboratory. J. Phys. Conf. Ser. 425, 72019.

(44) Konarev, P. V., Volkov, V. V., Sokolova, A. V., Koch, M. H. J., and Svergun, D. I. (2003) PRIMUS: A Windows PC-based system for small-angle scattering data analysis. J. Appl. Crystallogr. 36, 1277-1282.

(45) Hura, G. L., Budworth, H., Dyer, K. N., Rambo, R. P., Hammel, M., Mcmurray, C. T., and Tainer, J. a. (2013) Comprehensive objective maps of macromolecular conformations by quantitative SAXS analysis. Nat. Methods 10, 453-454.

(46) Petoukhov, M. V., Franke, D., Shkumatov, A. V., Tria, G., Kikhney, A. G., Gajda, M., Gorba, C., Mertens, H. D. T., Konarev, P. V., and Svergun, D. I. (2012) New developments in the ATSAS program package for small-angle scattering data analysis. J. Appl. Crystallogr. 45, 342-350.

(47) Semenyuk, A. V., and Svergun, D. I. (1991) GNOM - a program package for small-angle scattering data processing. J. Appl. Crystallogr. 24, 537-540.

(48) Durand, D., Vivès, C., Cannella, D., Pérez, J., Pebay-Peyroula, E., Vachette, P., and Fieschi, F. (2010) NADPH oxidase activator p67phox behaves in solution as a multidomain protein with semi-flexible linkers. J. Struct. Biol. 169, 
45-53.

(49) Sugio, S., Kashima, a, Mochizuki, S., Noda, M., and Kobayashi, K. (1999) Crystal structure of human serum albumin at 2.5 A resolution. Protein Eng. 12, 439-46.

(50) Curry, S., Mandelkow, H., Brick, P., and Franks, N. (1998) Crystal structure of human serum albumin complexed with fatty acid reveals an asymmetric distribution of binding sites. Nat. Struct. Biol. 5, 827-35.

(51) Svergun, D., Barberato, C., and Koch, M. H. (1995) CRYSOL - A program to evaluate X-ray solution scattering of biological macromolecules from atomic coordinates. J. Appl. Crystallogr. 28, 768-773.

(52) Chang, X., Keller, D., Bjoørn, S., and Led, J. J. (2001) Structure and folding of glucagon-like peptide-1-(7-36)amide in aqueous trifluoroethanol studied by NMR spectroscopy. Magn. Reson. Chem. 39, 477-483.

(53) Petoukhov, M. V, and Svergun, D. I. (2005) Global rigid body modeling of macromolecular complexes against small-angle scattering data. Biophys. J. 89, 1237-50.

(54) Bernadó, P., Mylonas, E., Petoukhov, M. V, Blackledge, M., and Svergun, D. I. (2007) Structural characterization of flexible proteins using small-angle X-ray scattering. J. Am. Chem. Soc. 129, 5656-5664.

(55) Tria, G., Mertens, H. D. T., Kachala, M., and Svergun, D. I. (2015) Advanced ensemble modelling of flexible macromolecules using X-ray solution scattering. IUCrJ 2, 207-217.

(56) Andersen, J. T., Daba, M. B., Berntzen, G., Michaelsen, T. E., and Sandlie, I. (2010) Cross-species binding analyses of mouse and human neonatal Fc receptor show dramatic differences in immunoglobulin $\mathrm{G}$ and albumin binding. J. Biol. Chem. 285, 4826-4836.

(57) Viuff, D., Antunes, F., Evans, L., Cameron, J., Dyrnesli, H., Thue Ravn, B., Stougaard, M., Thiam, K., Andersen, B., Kjærulff, S., and Howard, K. A. (2016) Generation of a double transgenic humanized neonatal Fc receptor (FcRn)/albumin mouse to study the pharmacokinetics of albumin-linked drugs. J. Control. Release 223, 22-30.

(58) Sleep, D., Cameron, J., and Evans, L. R. (2013) Biochimica et Biophysica Acta Albumin as a versatile platform for drug half-life extension is. BBA - Gen. Subj. 1830, 5526-5534.

(59) Schmidt, M. M., Townson, S. A., Andreucci, A. J., King, B. M., Schirmer, E. B., Murillo, A. J., Dombrowski, C., Tisdale, A. W., Lowden, P. A., Masci, A. L., Kovalchin, J. T., Erbe, D. V., Wittrup, K. D., Furfine, E. S., and Barnes, T. M. (2013) Crystal structure of an HSA/FcRn complex reveals recycling by competitive mimicry of HSA ligands at a pH-dependent hydrophobic interface. Structure 21, 1966-1978.

(60) Oganesyan, V., Damschroder, M. M., Cook, K. E., Li, Q., Gao, C., Wu, H., and Dall'Acqua, W. F. (2014) Structural insights into neonatal Fc receptor-based recycling mechanisms. J. Biol. Chem. 289, 7812-7824.

(61) Petersen, S. S., Kläning, E., Ebbesen, M. F., Andersen, B., Cameron, J., Sørensen, E. S., and Howard, K. A. (2015) Neonatal Fc Receptor Binding Tolerance Towards the Covalent Conjugation of Payloads to Cysteine 34 of Human Albumin Variants. Mol. Pharm. acs.molpharmaceut.5b00605.

(62) Gao, W., and Jusko, W. J. (2012) Target-mediated pharmacokinetic and pharmacodynamic model of exendin-4 in rats, monkeys, and humans. Drug Metab. Dispos. 40, 990-7.

(63) Zaias, J., Mineau, M., Cray, C., Yoon, D., and Altman, N. H. (2009) Reference values for serum proteins of common laboratory rodent strains. J. Am. Assoc. Lab. Anim. Sci. 48, 387-90.

(64) Selis, F., Schrepfer, R., Sanna, R., Scaramuzza, S., Tonon, G., Dedoni, S., Onali, P., Orsini, G., and Genovese, S. (2012) Enzymatic mono-pegylation of glucagon-like peptide 1 towards long lasting treatment of type 2 diabetes. Results Pharma Sci. 2, 58-65. 